\title{
NOTE
}

\section{A RECOMMENDATORY NOTE FOR THE CONTROL PROBLEM OF SCHISTOSOMIASIS IN CHINA}

The Chinese Government made a national project to eradicate schistosomiasis in that country within 7 or 10 years to follow and requested an aid of Japanese parasitologists. The following is a recommendatory note made by the delegation as a result of the observation and survey in several endemic areas in that country.

\section{The Present Status and Control Work of Schistosomiasis in China.}

The delegation was able to gain an outline of schistosomiasis and its control works in China after about two months round trip in that country. Considering the conditions in Japan in comparison with those in China, the impression and opinion of the delegation about this problem are summarized as follows.

a) Endemic foci of schistosomiasis in China are so numerous and their dimension is so vast (Bureau of preventive medicine, 1955).- Principal habitats of vector snails in Japan are limited to only five districts carrying a population of 400,000, whereas in China endemic foci are distributed over twelve provinces with a population of 10,000,000. The Szechwan Province (四川省), one of the endemic areas recently found, is as wide as Japanese Islands and believed to contain more than 60 endemic foci.

b) The habitat of vector snails is vast and rich in veriety.- In Japan major habitats of vector snails (Oncomelania nosophora). are found on the margin of small irrigation ditches except in marshy areas along rivers. In China on the observation in Tsingpu (青浦) and Wuschih (無錫), vector snails (Oncomelania hupensis) are found on the margin of almost all creeks, ditches and fish ponds. In Changshou (常熟) the delegation was able to observe vector snails on leaves and stems of reeds in shallow water of a marshy lake. Such was observed also in shallow water of Yangtse River (揚子江) near the city of Chinkiang (鎮江). At the suburbs of the City of Isching (宜興) vector snails were found on the margin of a small current between mountains. In the province of Kiangsu (江 蘇) alone the habitats of vector snails are so rich in variety.

c) Characteristic features of the control and treatment of schistosomiasis in China.- Generally speaking, the control programs are being carried out adequately and in good conditions. The control works in China were directed 
toward two directions, namely treatment work and control work including diagnostical one. The latter includes the control of night soil, defence against infection and molluscicidal work. The characteristic features of these works are manifested in the fact that the interrelations among the central government, administrative authorities and expert groups are compact, that the cooperation between the governmental organization and that of people in endemic areas as well as the cooperation between the organization of people and every individual in endemic areas is intimate. As for these points the delegation felt the Chinese situation was more advanced rather than in Japan. The delegation, however, was impressed by the fact that the preventive work appeared to be less emphasized as compared with treatment work. For instance, in Wuschih Institute for Schistosomiasis Control where the delegation stayed more than one month, only three doctors were engaged in the preventive work whereas in treatment work 7 doctors were on duty.

\section{The Control Work Should Be Emphasized.}

Provided that the direct objective of the control measures is only to remove pain of patients and to restore labor power lost by the disease, emphasis should be placed exclusively on the treatment of patients. The aim "schistosomiasis should be eradicated within seven years", however, requires that the preventive work should be emphasized, as Prof. Mao* said elsewhere.

The aim of the treatment of patients consists in 1) removal of their pain and clinical symptoms, 2) preventing the return of symptoms, 3) removal of the source of infection (ova in feces) and 4) securing labor power. From the view point of nation-wide prevention of this disease, however, only the third item above mentioned can serve as a workable measure. On this ground, effects of such preventive measures on the treatment of patients in a wide sense did not seem to have been properly evaluated although it holds true that the treatment of paitients per se can not be neglected.

\section{The Problem of Treatment.}

The observation made by the delegation revealed that the present objects for treatment procedures in China included all the asymptomous carriers. However, provided that the chief aim of schistosoma control is to prevent the disease, the treatment of all carriers might be impossible or if done at all ineffective, because in China the number of medical practitioners is rather too small to satisfy such demand (about 70,000 doctors among $600,000,000$ inhabitants). On the other hand, the treatment of schistosomiasis has not yet advanced to a satisfactory level. Provided that all carriers could receive the treatment, yet about $40 \%$ of them would still discharge ova in feces, thus rendering the danger of reinfection still undiminished.

a) The problem of carriers. - Here the carrier is understood as those who discharge schistosoma ova in feces manifesting no symptoms. The chief

\footnotetext{
* Director of the Institute of Parasitology, Shanghai.
} 
aim of the treatment of such carriers is to prevent those persons from falling ill in the future and to remove the source of infection (ova in feces). As above mentioned, the first item is less important for the eradication of schistosomiasis. The chief aim of the treatment of carriers is thus to be understood as being the prevention of the future illness. However, what type of carriers may have a higher possibility to fall sick remains yet to be solved in the future, because our knowledge concerning this problem is still very poor. The following is the theoretical consideration as to this problem.

The carrier: Here the word "carrier" is understood as an infected man with no symptoms nevertheless discharging ova in feces. Hence the carrier harbors necessarily female worms and their ova are being discharged into the intestinal lumen after breaking its wall. Such facts mean that lesions are present more or less on and near the wall. It might be probable however, that the lesions cover too small an area to give rise to a clinical symptom.

The carrier and manifestation of symptoms: When worms infested amount to a certain number the pathological changes due to their presence would be so conspicuous as to manifest symptoms soon afterwards, and repeated reinfections would increase the probability of manifesting symptoms even when the initial worm number is not so numerous. In such cases individual disposition as well as acquired immunity can play a considerable roll upon arising clinical symptoms. As our knowledge concerning such is yet very poor, these are the problems to be solved in the future.

b) The treatment problem including patients in a more advanced stage.- The cure of patients per se is very necessary. In China the methods of treatment are now under vigorous study. Among them the following called attention of the delegation.

1. The antimon preparations applied: As the therapeutic agent in China, as in most of European and American countries, potassium antimony tartarate is chiefly applied. The delegation considers that the application of sodium antimony tartarate would be rather convenient. In Japan the latter preparations have been used exculsively since thirty years ago. because it has been proved to be as effective as the former with less side effects (Miyagawa, 1923). According to experiments achieved by the Chinese experts as well as by the delegation it was indicated that sodium salt was likely to be more effective although significance of this difference was equivocal when analyzed statistically. The side effects of the potassium salt appeared rather more severe. Along with this it is to be noticed that the complication of beriberi was found in no rare cases. Such is an objective of further study.

2. A short term treatment: In Japan the technic of short term treatment has not been worked out, because the patients are not so numerous now. In China where a great number of patients waits the treatment, however, such is considered to be important in view of facilitation for treatments 
as well as for economical reason.

3. The problem of alleviation of side effects: The antidote to alleviate the side effects has not been introduced in Japan. On this point the delegation tentatively applied one of liver protectives (methionine preparation) and had an impression that it was somewhat effective. The applicability of Vitamin B in case of combined beriberi is also suggested.

4. The treatment of patients in the end stage: In Japan the patients in the end stage are so few at present that no special treatment on such patients was introduced, except the application of a troicar with a hole devised by Sugiura (1949) for removal of ascites. In China the application of several materia medica for removal of ascites was under investigation with a certain success (Institute Schistosom. in Chekiang, 1956; Ting, 1956; Health Center of Chekiang Prov., 1956) what are to be highly evaluated. Here it is to be mentioned that the experience in the application of cortison by the delegation was able to lead to a certain success for its removal.

\section{The Problem of Diagnosis.}

Here several topics as to diagnosis are to be discussed briefly.

a) The diagnosis of carriers.- At present in China the positive case for ova is screened out in advance by the application of skin test (Mao, 1956). The antigen from extract of schistosome body is under production in the Institute of Parasitology in Nanking. Those positive for skin test are examined for ova with the technic to hatch out miracidia as well as with sedimentation technic. Such procedure is highly appreciated by the delegation as a procedure adequate in China, where a large number of suspected carriers may exist in the vast endemic areas.

b) The prognostic diagnosis of carriers.- The prognosis of carriers is important in connection with the treatment. The problem of what type of carriers will fall ill in the future and what other type will manifest no symptom remains to be solved. To solve these problems, some animal experiments should be carried out along with clinical observations.

\section{$V$. The Control of Snails Should Be Preferred to That of Nightsoil.}

The delegation considers that the most effective method for combating the disease is to control snail vectors. The snail control should be preferred to that of nightsoil. The nightsoil control per se is important in China. It would be very difficult, however, to realize the nightsoil control perfectly, because performance would often be confronted by the need for upsetting habits and customs of inhabitants deeply rooted in their life. As compared with the nightsoil control the procedure of snail control is much easier to be carried out because the habitants as well as the range of movement of snails are much limited.

\section{The Problem of Nightsoil Control.}

a) The different features of nightsoil control between Japan and China.- 
In China the problem of nightsoil control is closely related with the protection of water source (source of water supply). Therefore it is more important and complicated as compared with that in Japan. In Japan each family in the country-side has its privy (water closet) and family members use it. Defecation in the field is rare. Essentials of the nightsoil control in Japan is to kill parasite ova contained in it or to prevent their contact with snails.

In Japan almost all families in the endemic area have private wells to supply drinking water. The inhabitants wash clothes and implements with water from such wells. So here can occur no necessity of protection of water source against the cercarial infection. In China, particulary in endemic areas of schistosomiasis, almost all inhabitants utilize nightsoil backets (Matong) provided in all houses, washing them in water in creeks. At the same time, inhabitants of these areas drink and utilize creek water for all purposes for a long year. Thus the control of nightsoil would be more complicated as compared with that in Japan.

b) On the present praxis of the nightsoil control in China.- The present. procedure of the nightsoil control in China, as far as the delegation observed, is reasonable and practical. Its technical and educational guidance appeared to be properly practiced. The delegation had an impression, however, that their future success would confront with a considerable difficulty. For instance, as a member of Wuschih Institute told us, in case of mass examination of stools those who offered them for examination were about $90 \%$ of all residents in the Wuschih Model Control area. In other words about $10 \%$ of them offered no materials even in such a model area. In this area the prohibition of washing of Matong in a creek was repeatedly propagated and taught in every chance, namely by lectures in assemblies, by model miniatures and posters, etc. But in spite of these efforts no complete abolition of washing of Matong in creeks was yet achieved. The delegation itself observed early in the morning persons washing Matong in a creek during the stay in this model area.

Some lack of administrative cautions was also revealed. (Several covers of nightsoil jars in the field were seen left in a broken condition in the model area.)

The chief obstacles against securing success of the nightsoil control project would be the habits and customs deeply rooted in the inhabitants. They are to be completely changed to secure success of the project but the inhabitants would resist against their change instinctively. People whose cultural level is comparatively low appear to be more attracted to a direct interest, however small it may be, than a larger public one simply because the latter is indirect. In order to form a new habit or custom the connection of other direct interest of economical nature with such projects may often secure its success.

c) The control of reservoir hosts.- In some areas the infection of 
vector snails with schistosom may originate from human feces but in some others it may originate chiefly from that of the reservoir host. In Japan the high incidence of infection of snail vectors along the river of Chikugo was originated from feces of cattle which were pastured in its grassy river bed. In China the baffalo could be a chief source of infection in snails in certain areas, yet the survey on reservoir hosts is poor in China ( $\mathrm{Wu}, 1956)$ and should be carried out in the future.

VII. The Environmental Snail Control Should Be Taken as Fundamental.

At present several technics of snail control are either under consideration or in the initial procedure. These are summarized as follows.

a) Physico-chemical control.

1. Physical methods: molluscicidal technic with hot water; direct burning; burning utilizing a flame projector.

2. Chemical molluscicides: sodium pentachlorophenate; calcium arsenite; bensen hexachloride (B. H. C.) ; calcium cyanamide.

b) Environmental control:

1. Burying snails with soil.

2. Blocking the margin of creeks with stone.

3. Cementing ditches.

4. Development of marshy areas.

Among these control methods above mentioned the delegation has the opinion that the environmental control should be taken as a fundamental one. The physico-chemical methods of attack, however, is effective when properly applied and they should be applied side by side with the former.

VIII. Physico-Chemical Control of Vector Snails.

a) Physical molluscicidal technics.- Among physical molluscicidal technics the delegation highly appreciates working out the molluscicidal technic with hot water and that with flame projectors settled in boats. Here the flaming gas was produced from coal and vapor. The application of these technics against snails on the margin of creeks is very convenient. The application of the portable flame projectors utilizing petroleum oil or others, at the same time, could be applied in an area where no boat could approach.

b) Chemical molluscicidal technics. - The delegation observed the actual procedure of the molluscicidal technic in Kiangsu Province, where calcium arsenite (Su, 1954; 1956) and B. H. C. (Sun, 1956) were used as agents and both proved to be effective for this purpose. The apparatus was settled in a boat and the drug was mixed with water and sprayed by motor craft. In Japan calcium cyanamide was applied for this purpose previously but in recent years sodium pentachlorophenate (P. C. P.) has been used chiefly because the former had a probability to be utilized by the inhabitants as a fertilizer instead of as molluscicide. Japan had no experience of application of calcium arsenite and B. H. C. 
The delegation considers that the application of calcium arsenite for molluscicidal purpose in this country is very practical. According to the Chinese study, calcium arsenite is a food poison for snails and insoluble in water and therefore no water contamination can occur after its application.

During the stay in China the delegation examined the food taking habit of vector snails (Oncomelania hupensis) and recognized that it took calcium arsenite with mud of its habitat and found that its intake diminished as the ratio of the former in mud became smaller (Komiya et al.,1957). In China calcium arsenite is being utilized as a form of suspension in water but its dusting technic in certain areas could be considered.

Sodium pentachlorphenate is soluble in water and this facilitates spraying. In creek areas, however, as is the case in Yangtse Delta, the water of creeks sometimes would be contaminated with drug. In those areas the inhabitants often culture fish in creeks and sodium pentachlorphenate was proved to be poisonous for fish in a concentration of one ppm. There exists the danger against human beings because the inhabitants in these areas usually drink creek water. In the habitat of vector snails where no such danger can be considered, sodium pentachlorphenate as well as calcium cyanamide could be applicable. Beside the above mentioned several molluscicidal agents are now under investigation. Among these Pa Dou (Croton tiglium) (Chou et al., 1952) and Tsia Tsu Ping (residuals of seed materials of Camellia sp. after extracting oil) are noticeable. Both are special products from China and are effective (ca. $1 \%$ concentration) as molluscicides.

It is to be noticed that sodium pentachlorphenate may increase the resistance of vector snails. In connection with this, whether calcium arsenite would produce resistance of vector snails is to be studied.

IX. Environmental Control of Vector Snails.

a) The experience in Japan.- In Japan during the initial period of schistosome control the emphasis was laid on nightsoil control but later the chemical attack on vector snails was introduced and has become the chief method of attack and just before the II World War the vector snails diminished considerably. During and just after the war, however, Japanese social situations made it difficult to carry out such chemical control procedures. As a result just before the time when chemical attack on snails was again undertaken, the dimension of habitat areas as well as the density of snail population were found rather increased. This experience revealed that the chemical attack on snails was effective in sofar as it was repeated continuously, but when such procedures were suspended for a certain time interval the snail population would increase rapidly and after a certain period it would surpass the number present before the commencement of control.

After the war, in 1951, the cementing of ditches was adopted by the authorities as a chief method of environmental control and the financial aid for 
this purpose was introduced by the Government. As a result of this, in the year 1956, in the endemic area of Katayama, where ditch cementing program was most advanced and about $25 \%$ of all ditches were already cemented, the vector snails in such ditches were found virtually all eradicated.

On the other hand, in Japan, there were several cases where a natural environmental change resulted in the anihilation of snails. The following shows examples of such cases.

1. The endemic area at Akatsuka Village (in the District of Tokyo; near the city of Akabane): According to the previous records, vector snails were found in this area about twenty to thirty years ago. Recently this area was reclaimed as a building site of factories and resulted in a status that no vector snails were found.

2. The endemic area in the basin of Kokai River: Twenty years ago the basin of Kokai River was an actual habitat of vector snails but a flood occured several years ago and dirty water stagnated there for 2 to 3 weeks and afterwards no snail has been found there ever since up to now.

3. The area of Ukishima in the Prefecture of Shizuoka: Twenty years ago this area was known as an actual habitat of vector snails. At that time this area was a vast marsh but afterwards the development was undertaken to convert it to a rice field as it is now. At present some parts of this area are lower than the sea level and sometimes sea water is said to flow into this area through the lock gate. At any rate vector snails are scarcely seen in this area at present.

Examples above mentioned reveal that natual environmental changes unfavored the existence of vector snails and resulted in anihilation of them.

b) Factors unfavoring the existence of vector snails (Oncomelania sp.).-

1. Factors conditioning the habitat, food habit and breeding conditions: Among factors conditioning the habitat are physical (temperature, light intensity, water, humidity, etc.), chemical (salinity, iron balance, $\mathrm{pH}$, etc.) and biological (vegetation, food materials, natural enemies, etc.). The essentials among them, however, are the two; namely, the ample existence of food for the maintenance of individuals and breeding conditions. The others are considered to be of secondary importance from the view point of control. Essential factors conditioning the above two, however, are yet very poorly known. But some fundamentals may be conceivable.

1,1. The food preference of snails :

It is suggested that Oncomelania species are primarily rhytophagous. The results of observation of the delegation in the Wuschih area also suggested that the chief food stuff of them were fresh water algae (Diatoms and Chrolophycae) (Komiya et al. 1957). The food preference of vector snails is to be studied more extensively in the future. 
1,2. Breeding conditions:

The Chinese observation suggested that Oncomelania hupensis laid ova preferably on the surface of wet mud (Wang et al., 1956a), although they were found occasionally on the root of weeds, on brick and stone and even on the shell of certain bivalvae (Unio, Anodonta etc.). Around each ova a thin wall of mud was observed without exception and this suggests that mud would be necessary for the oviposition of Oncomelania sp. Thus the chief aim of attack on vector snails is to rule out the chief food stuff, namely algae and the complete removal of mud from their habitats.

Taking into consideration the fact that one of the favorite habitats of algae are wet surface of mud, the point of attack could be concentrated on the removal of wet mud in their habitats.

2. The actual habitat of vector snails in China: On the margin of creeks and ditches in the vicinity of Wuschih the main habitat of vector snails were confined to the surface of soil of about $1 \mathrm{~m}$ width from water level. Naturally in accordance with the webb and tide of water the snails are occasionally found on the surface of soil beneath the water level and on the stem of water weeds. Except the very young, however, almost all snails appeared soon to creep out of water and laid theirselves on the wet surface of soil above the water level.

The results of the above observation would lead to the conclusion that the chief aim of the environmental control is to let no mud remain on the margin of creeks or ditches.

c) The evaluation of various methods of environmental control.-

1. Burying snails with soil: This is frequently applied in China. This method is one of the simplest technics of environmental control, and if it is properly carried out it will be considerably effective (Wang et al., 1956b). It is to be noticed, however, that no individuals should be left unburied, that they should be buried at least $10 \mathrm{~cm}$ or deeper and that they could creep up to the surface to soil along the stem of weeds when such were found in the burying soil. The least economical expense would be required for it. On the condition that all land belongs to the state this technic would be easily carried out and effective particulary in the habitats along the irrigation ditches.

2. Blocking the water margin of creeks with stone: The water margin of creeks, swamps, marshes and ponds, covering a width of about $1 \mathrm{~m}$ from the water edge and also several decimeters beneath the water level, should be blocked with stone and the crevice between stones should be cemented completely. The delegation had an impression that this technic could be applied to the major habitats along creeks. It would need considerable expense but the stone materials for this purpose appeared to be easily available in certain districts (for instance in the district of Wuschih).

3. Cementing ditches: This method could be applied to irrigatoin ditches. In Japan this method of control has been in practice by the financial aid of 
the Government. After the realization of cementing the crop of cererials (chiefly rice) will be increased and will compensate for the expenditure to a certain grade. The administrative supervision should be necessary after the construction in order to prevent the vegetation and silt.

4. The development of marshy areas: The development of the marshy area into the cultivated land or others is one of the most radical and effective methods of environmental snail control. The habitat where the delegation observed in the district of Changshou (常熟) was a shallow shoal with reeds. By the aid of a dredger such an area could become deep enough to allow no growth of reeds or other vegetation. The dredged mud or sand could be utilized to fill up the shore.

Generally speaking, the method of environmental control would spend much money. This method, however, will deserve the expense or, in certain cases, it will pay off when the control work is combined with agricultural, irrigation and fishery developmental works.

\section{REFERENCES}

Bureau of Preventive Medicine, Department of Health, Peoples Republic of China (1955) : Materials for Prevention of Disease, No. 5 (text in Chinese).

Chou, H. J. et al. (1952): Study of Chinese materia medica (Croton tiglium) as an agent for molluscicidal purpose. Chunghua Hsin Ishue (China New Medicine), 3 (6), 457-493 (text in Chinese).

Health Center of Chekiang Province (1956): Ascites weed as an agent for the treatment of ascites of schistosomiasis in its end stage. Chunghua Ishue Tsashih (China M. J.), 42 (5), 421-423 (text in Chinese).

Institute of Schistosomiasis in Chekiang (1956): Chun-Tsuong and Hu-Lu as a treatment agent for schistosomiasis of end stage. Chunghua Ishue Tsashih (China M. J.), 42 (5), 419-420 (text in Chinese).

Komiya, Y. et al. (1957): Study on the food habit of Oncomelania I. A new simple technic for studying the food habit of Oncomelania and an information on the foodhabit of Oncomelania hupensis. Jap. J. Ecol., 7 (1), 18-22 (text in Japanese with English summary).

Mao, C. P. (1954): Several problems to be solved on schistosomiasis in China. Chunghua Weisang Tsashih (Chinese J. Hyg.), (2), 111-116 (text in Chinese).

Mao, C. P. (1956): The significance and technic of the interdermal reaction of schistosomiasis. Dachung Ishue (Peoples Med.), (94), 436-438 (text in Chinese).

Miyagawa, Y. (1923) : The treatment of schistosomiasis by tartar emetic, "Stibnal" made in Japan. J. Exper. Med., 9. 107 (text in Japanese).

$\mathrm{Su}$, T. L. (1954): Chemical control of snail vetors as a measure of schistosoma control, particulary Calcium arsenate as its agent. Chunghua Weisang Tsashih (Chinese J. Hyg.), (2), 81-94 (text in Chinese).

$\mathrm{Su}, \mathrm{T}$. L. (1956) : Calcium arsenate as an agents of chemical molluscicide. Dachung Ishue (Peoples Med.), (94), 426-427 (text in Chinese).

Sugiura, S. (1949): A proposal of a simple internal technic for ascites due to livercirrgosis. Tokyo Ihishinshi, 66 (12), 25-30 (text in Japanese). 
Sun, S. C. (1956): A prelimenary field experiment of B.H.C. as an molluscicidal agent. Dachung Ishue (Peoples Med.), (94), 420-421 (text in Chinese).

Ting, T. C. (1956): Euphorbia pekinensis as an agent for the treatment of ascites in the end stage of schistosomiasis. Chunghua Ishue Isashih (China M. J.), 42 (5), 424-425 (text in Chinese).

Wang, P. S. et al. (1956a) : Study on the reproduction and development of Oncomelania hupensis. Ibid., 42 (5), 426-440 (text in Chinese).

Wang, P. S. et al. (1956b): Experiments on burying technic of vector snails as a control measure of schistosomiasis. Ibid., 42 (6), 401-412 (text in Chinese).

Chief, Japanese Medical Delegation

YOSHITAKA KOMIYA ${ }^{1)}$

for the aid of the control of

schistosomiasis in China; Department

of Parasitology, National Institute

of Health, Tokyo ${ }^{2)}$

Received: October 8th, 1957

1)小宮義孝, 2)国立予防衛生研究所寄生虫部 